\title{
Rheumatoid Arthritis Classification Criteria: Moving with the Times
}

The last 3 decades have seen a wholesale change in the approach to the management of rheumatoid arthritis (RA). The emphasis has changed from symptom control, moderation of disease progression after structural damage had occurred, and accommodation of disability, to modern outcome-driven strategies. Rheumatologists now have treat to $\operatorname{target}^{1}$, remission induction ${ }^{2,3}$, damage prevention strategies $^{4}$, and increasingly stretch targets of maintaining productivity $^{5}$ and drug-free remission ${ }^{6}$. These management approaches and outcome targets demonstrate how much the treatment and our expectations have changed with advancing knowledge and new therapies in RA.

It was not until cohort studies of the early 1980s demonstrated the true consequence of uncontrolled inflammation that attitudes to RA management began to change ${ }^{7}$. It was in 1987 that the American College of Rheumatology (ACR) revised the criteria for the classification of $\mathrm{RA}^{8}$. The criteria were developed to improve the homogeneity of patients entered into clinical trials with established disease. However, the pathognomonic features of RA such as classical clinical deformity, periarticular joint erosion, and nodules occur late in the disease process. The fact that the 1987 ACR criteria included the latter diminished their value in early disease, and several studies demonstrated diminished sensitivity for diagnosis of RA in the early months of symptoms ${ }^{9,10}$. In recognition of this and also of the specialty's change in approach to the management of RA, it was timely for the classification criteria for RA to be revised jointly by the ACR and the European League Against Rheumatism (EULAR) in $2010^{11}$.

The working group of the ACR and EULAR determined that the 1987 ACR classification for RA, for the reasons outlined above, hampered recruitment of patients with early disease to intervention studies in $\mathrm{RA}^{11}$. The remit was to identify patients newly presenting with undifferentiated inflammatory synovitis, who were likely to have persistent and/or erosive disease. Thus the new criteria would go hand in hand with the accepted benefit of early diagnosis and intervention. Additionally, the new criteria were to act as a basis for commencing disease-modifying therapy and also to remain applicable in patients presenting with late disease. The final criteria omit radiographic changes and the presence of nodules and concentrate on joint involvement, serology, including anti-citrullinated protein antibody (ACPA) testing, markers of acute-phase response, and symptom duration. A numerical value determines the likelihood of definite RA. As a result of this reclassification, some patients that have previously been recruited to studies in early undifferentiated inflammatory arthritis may well have been classified as RA according to the revised criteria ${ }^{12}$.

In this issue of The Journal the Canadian Early Arthritis cohort $(\mathrm{CATCH})$ investigators present findings from a large, early synovitis cohort and examine disease activity in patients meeting the old (1987) versus the new (2010) criteria $^{13}$. CATCH is a nationwide, multicenter, prospective, real-world cohort of adults with early inflammatory arthritis, which started recruiting in 2007. The participants should be congratulated on establishing a national early RA cohort providing important data on the outcome and management of early RA in Canada. Caution may be required regarding the national applicability of the findings, given that 2 provinces, Ontario and Quebec, provided over $80 \%$ of the patients.

The results are clearly presented in the $\mathrm{CATCH}$ report, but there are some interesting observations. Of note, there is a trend to reduced symptom duration at time of presentation between 2007 and 2011. It is established that the best predictor of entering remission after intervention with conventional disease-modifying drugs in RA is short disease duration $^{14}$ and as such these data show promise. Although significance is not reached, it may be an early sign of the success of the many initiatives undertaken by Canadian rheumatologists to promote awareness of RA among both the general public and health professionals. Many centers worldwide have worked tirelessly to establish where the delays lie in the assessment pathway for inflammatory arthritis and reduce symptom duration at time of presentation to the rheumatologist, but there is little objective evidence of reliable effective strategies ${ }^{15}$. The group have also demonstrated that patients presenting with disease satisfy-

See Canadian Early Arthritis Cohort, page 2071

Personal non-commercial use only. The Journal of Rheumatology Copyright @ 2012 . All rights reserved. 
ing the 2010 criteria are less severe than patients presenting with disease satisfying the 1987 criteria, but are also less likely to be treated with methotrexate. Recognition of such findings may be paramount in improving patient outcomes.

Hence, the new criteria herald a new era for researchers in RA, creating opportunities for rheumatologists to enroll real-life patients with early RA into therapeutic clinical trials and potentially provide data for best practice at the earliest stages of RA. For clinicians, an understanding of the lack of comparability of new and historically classified RA cohorts is essential as new studies using the new ACR classification criteria emerge. The CATCH study group have demonstrated that patients with less severe disease are likely to be identified using the new criteria, a fact that alone may offer a greater opportunity for intervention and optimal outcomes. We may hypothesize that the development of the new criteria for the classification of RA may in themselves improve patient outcomes. Further caution may also be required. A recent review has suggested that the new RA classification criteria improve sensitivity for the diagnosis of RA, but specificity is decreased ${ }^{16}$. As such, patients fulfilling the criteria have a high probability of disease, but not fulfilling the criteria does not rule out RA. Equally, the CATCH cohort has demonstrated that patients with less severe disease may be identified and their natural history and prognosis may differ from what we currently understand from RA cohort studies. For example: a higher proportion of patients may enter remission and be able to stop therapy. Although therapy guidelines suggest rheumatologists should slowly withdraw therapy once a remission state is achieved, there is a dearth of data allowing clinicians to accurately predict which patients will successfully remain therapy-free. Thus the research agenda is set. In essence the 2010 ACR/EULAR classification criteria for RA may just open the "window of opportunity" for intervention even wider, providing rheumatologists and patients a chance of optimizing therapy and best possible outcomes.

\section{MARK A. QUINN, MBChB, MRCP,}

Clinical Director of Specialist Medicine/Consultant Rheumatologist, The York Hospital,

York Hospital NHS Foundation Trust,

York, YO318HE UK

Address correspondence to Dr.Quinn; E-mail: mark.quinn@york.nhs.uk

\section{REFERENCES}

1. Smolen JS, Aletaha D, Bijlsma JW, Breedveld FC, Boumpas D, Murmester G, et al; T2T Expert Committee. Treating rheumatoid arthritis to target: Recommendations of an international task force. Ann Rheum Dis 2010;69:631-7.

2. Wevers-de Boer K, Visser K, Heimans L, Ronday HK, Molenaar E, Groenendael JH, et al. Remission induction therapy with methotrexate and prednisone in patients with early rheumatoid and undifferentiated arthritis (the IMPROVED study). Ann Rheum Dis 2012;71:1472-7.

3. Quinn MA, Conaghan PG, O'Connor PJ, Karim Z, Greenstein A, Brown A, et al. Very early treatment with infliximab in addition to
Methotrexate in Early, Poor-Prognosis Rheumatoid Arthritis reduces magnetic resonance imaging evidence of synovitis and damage, with sustained benefit after infliximab withdrawal; results from a 12-month randomized, double-blind, placebo-controlled trial. Arthritis Rheum 2005;52:27-35.

4. Smolen JS, Han C, Bala M, Maini RN, Kalden JR, van der Heijde D, et al; ATTRACT Study Group. Evidence of radiographic benefit of treatment with infliximab plus methotrexate in rheumatoid arthritis patients who had no clinical improvement: A detailed sub analysis of data from the Anti-Tumor Necrosis Factor Trial in Rheumatoid Arthritis with Concomitant Therapy study. Arthritis Rheum 2005;52:1020-30.

5. Bejarano V, Quinn M, Conaghan PG, Reece R, Keenan AM, Walker D, et al; Yorkshire Early Arthritis Register Consortium. Effect of the early use of the anti-tumor necrosis factor adalimumab on the prevention of job loss in patients with early rheumatoid arthritis. Arthritis Rheum 2008;59:1467-74.

6. van der Woude D, Visser K, Klarenbeek NB, Ronday HK, Peeters AJ, Kerstens PJ, et al. Sustained drug-free remission in rheumatoid arthritis after DAS-driven or non-DAS-driven therapy: A comparison of two cohort studies. Rheumatology 2012;51:1120-8.

7. Pincus T, Callahan LF, Sale WG, Brooks AL, Payne LE, Vaughn WK. Severe functional declines, work disability, and increased mortality in seventy-five rheumatoid arthritis patients studied over nine years. Arthritis Rheum 1984;27:864-72.

8. Arnett FC, Edworthy SM, Bloch DA, McShane DJ, Fries JF, Cooper NS, et al. The American Rheumatism Association 1987 revised criteria for the classification of rheumatoid arthritis. Arthritis Rheum 1988;31:315-24.

9. Green M, Marzo-Ortega H, McGonagle D, Wakefield R, Proudman $\mathrm{S}$, Conaghan P, et al. Persistence of mild, early inflammatory arthritis: The importance of disease duration, rheumatoid factor, and the shared epitope. Arthritis Rheum 1999;42:2184-8.

10. Harrison BJ, Symmons DP, Barrett EM, Silman AJ. The performance of the 1987 ARA classification criteria for rheumatoid arthritis in a population based cohort of patients with early inflammatory polyarthritis. J Rheumatol 1998;25:2324-30.

11. Aletaha D, Neogi T, Silman AJ, Funovits J, Felson DT, Bingham CO 3rd, et al. 2010 Rheumatoid arthritis classification criteria: An American College of Rheumatology/European League Against Rheumatism collaborative initiative. Ann Rheum Dis 2010;69:1580-8.

12. Krabben A, Huizinga TW, van der Helm-van Mil AH. Undifferentiated arthritis characteristics and outcomes when applying the 2010 and 1987 criteria for rheumatoid arthritis. Ann Rheum Dis 2012;71:238-41.

13. Bykerk VP, Jamal S, Boire G, Hitchon CA, Haraoui B, Pope JE, et al. The Canadian Early Arthritis Cohort (CATCH): patients with new onset synovitis meeting the 2010 ACR/EULAR classification criteria but not the 1987 ACR classification criteria present with less severe disease activity. J Rheumatol 2012;39:2071-80.

14. Anderson JJ, Wells G, Verhoeven AC, Felson DT. Factors predicting response to treatment in rheumatoid arthritis. The importance of disease duration. Arthritis Rheum 2000;43:22-9.

15. Villeneuve E, Nam JL, Bell MJ, Deighton CM, Felson DT, Hazes JM, et al. A systematic literature review of strategies promoting early referral and reducing delays in the diagnosis and management of inflammatory arthritis. Ann Rheum Dis 2012 Apr 24. [Epub ahead of print]

16. van der Helm-van Mil AH, Huizinga TW. The 2010 ACR/EULAR criteria for rheumatoid arthritis: Do they affect the classification or diagnosis of rheumatoid arthritis? Ann Rheum Dis 2012 May 12. [Epub ahead of print]

J Rheumatol 2012;39:2062-3; doi:10.3899/jrheum.121000 Personal non-commercial use only. The Journal of Rheumatology Copyright (C) 2012. All rights reserved. 